\title{
Advocacy and Allyship by Men for Women in Engineering-related Fields at the College Level
}

\section{Dr. Brian Kirkmeyer, Miami University}

Brian Kirkmeyer is the Karen Buchwald Wright Senior Assistant Dean for Student Success and Instructor in the College of Engineering and Computing at Miami University in Oxford, Ohio. His background includes BS, MS and PhD degrees in Materials Science and Engineering (specialization in polymers), the former from Purdue University and the latter two from the University of Pennsylvania. He has work experiences in automotive electronics (Delphi Automotive Systems) and consumer products (International Flavors and Fragrances) prior to his current role. He served on the executive committee of the ASEE Women in Engineering division from 2010 to present.

\section{Dr. Michael D. Johnson, Texas A\&M University}

Dr. Michael D. Johnson is a professor in the Department of Engineering Technology and Industrial Distribution at Texas A\&M University. Prior to joining the faculty at Texas A\&M, he was a senior product development engineer at the 3M Corporate Research Laboratory in St. Paul, Minnesota. He received his B.S. in mechanical engineering from Michigan State University and his S.M. and Ph.D. from the Massachusetts Institute of Technology. Dr. Johnson's research focuses on engineering education; design tools; specifically, the cost modeling and analysis of product development and manufacturing systems; and computer-aided design methodology.

\section{Dr. Lisa Abrams, The Ohio State University}

Dr. Lisa Abrams is currently the Associate Chair for the Department of Engineering Education at The Ohio State University (OSU). She received her Bachelor's and Master's Degrees in Mechanical Engineering and $\mathrm{PhD}$ degree in Industrial Engineering from Ohio State. She has seven years of industry experience in the areas of Design and Consulting. Her research focuses on the recruitment, retention, and success of undergraduate students, especially those populations who are under-represented in engineering. She has developed and taught a wide variety of engineering courses in First Year Engineering and Mechanical Engineering at Ohio State. She has received numerous teaching awards in the last five years at both the College and the Departmental level at OSU.

\section{Dr. Roger A. Green, North Dakota State University}

Roger Green received the B.S. degree in electrical and computer engineering and the M.S. and Ph.D. degrees in electrical engineering from the University of Wyoming in 1992, 1994, and 1998, respectively. During his Ph.D. studies, he also obtained a graduate minor in statistics.

He is currently an Associate Professor and Undergraduate Coordinator with the Electrical and Computer Engineering department at North Dakota State University, where he teaches courses and conducts research in signal processing.

Since its inception in 2008, Dr. Green has been an active member of the NDSU Advance FORWARD Advocates, a group of male faculty dedicated to effecting departmental and institutional change in support of gender equality. As part of this group, he regularly trains men, at NDSU and other institutions, to better serve as gender equity allies.

\section{Dr. Lyndsey McMillon-Brown, NASA Glenn Research Center}

Lyndsey McMillon-Brown is a researcher at NASA Glenn Research Center. Lyndsey earned her B.S in Mechanical and Manufacturing Engineering from Miami University (2013), she then completed her M.S and Ph.D. in Chemical Engineering at Yale University (2019). Her dissertation work focused on developing novel materials and patterns for advanced light trapping in solar cells. Lyndsey has worked on a variety of space solar cell-related programs including thin film and organic cell development and durability studies. She is currently the Principle Investigator on a research effort to develop perovskite solar cells for space. Outside of the lab, Lyndsey is dedicated to increasing opportunities for underrepresented individuals in STEM fields. 


\section{ASEE ANNUAL CONFERENCE}

Virtual Meeting | July 26-29, 2021 | Pacific Daylight Time

\section{Dr. Sharon A. Jones P.E., University of Washington Bothell}

Sharon Jones is the Vice Chancellor for Academic Affairs at the University of Washington Bothell. She is a licensed civil engineer with degrees from Columbia University, the University of Florida, and Carnegie Mellon University. Her research interests focus on applying decision-making methods to evaluate sustainability policies with emphases on infrastructure, developing economies, and particular industrial sectors. She is also interested in engineering pedagogy, promoting diversity in the engineering profession, and developing opportunities to bridge engineering and the liberal arts.

\section{Prof. Philip Ritchey, Texas A\&M University}

Philip Ritchey is an Instructional Assistant Professor in the Department of Computer Science and Engineering at Texas A\&M University. He earned the $\mathrm{PhD}$ in Computer Science from Purdue University in 2015 and has been at Texas A\&M ever since. He teaches introductory-level computer sciences courses as well as advanced courses in software engineering and security. Recently, he is particularly interested in $\mathrm{K}-12$ computer science teacher education. 


\title{
Advocacy and allyship by men for women in engineering-related fields at the college level
}

\begin{abstract}
Diversity enables better and more creative problem solving, with greater financial impact on organizations, according to multiple studies in the past 10 years. One long-standing limitation on diversity in technology fields is the persistently-low representation of females. This is often seen in the collegiate environment more than in the professional world, and greater efforts need to be made in college classrooms and labs to address it. Most succinctly, more men need to directly involve themselves as advocates for and allies of women. This panel engages with professionals of both binary gender identities who currently ally and advocate for women in engineering, computing, and technology fields. The goals of the panel are to identify common reasons why men should advocate for women, create support around the simple actions that can be taken in advocacy, and encourage greater allyship for women in the academic world and beyond. The panelists include both men and women from across multiple intersectional identities. The questions include (1) for what reasons are you an ally or advocate for women in engineeringrelated fields, (2) what experiences have you had in which you have had to take immediate action as an advocate or ally, (3) what do you recommend for easy-to-implement actions to advocate, and (4) how can advocates and allies help implement change at their own institutions. For the paper, each panelist would be asked these questions and their answers would be provided unedited, followed by a summary discussion of actionable items. For the panel presentation session, each panelist will have the opportunity to highlight aspects of their answers bring life to their thoughts to each question and together with other members of the panel can build for an indepth discussion.
\end{abstract}

\section{Introduction}

This paper presents perspectives from five engineering professionals, either in higher education or a government institute, with experience related to increasing the overall presence of women in engineering, computing, and technology fields. The panelists represent multiple lived realities and intersectional demographic identities. The content of this paper was generated by collecting the individual responses of each panelist to a set of posed questions. These questions include:

1. For what reasons are you an ally or advocate for women in engineering-related fields?

2. What experiences have you had in which you have had to take immediate action as an advocate or ally?

3. What do you recommend for easy-to-implement actions to advocate?

4. How can advocates and allies help implement change at their own institutions?

Resources and Relevant Literature 
In the academe and the wider world there is a growing awareness of the importance of allies. There is also a growing interest among people of dominant or in-groups in becoming allies. Louis, et al. [1] provide this definition: "Allyship refers to members of advantaged groups engaging in committed action to improve the treatment and status of a disadvantaged group". $\mathrm{Ng}$, et al. [2] notes the importance of focusing on the out-group "from a social justice lens". Craig, et al. [3] differentiate between allyship and solidarity; solidary is when there is shared disadvantage with the out-group, while allyship requires awareness of in-group membership and associated privilege.

Radke, et al. [4] highlight four motivations for allyship: in-group focused, out-group focused, personal, and morality-based. In-group focused motivations are about maintaining the status quo ante. Out-group focused based on genuinely helping others and reject the "less than" status of the out-group. Personal motivation is self-centered and narcissistic in nature, while morality motivation is based on doing what is right. Allyship for gender equity has a long history and has been known as men's anti-sexism or pro-feminism [5]. Berkowitz [6] documented the importance of men in promoting the prevention of sexual assault. A large portion of the elements from that work were also relevant for male faculty allies.

Allyship is contextual and should be based on the groups involved, the political context, and the societal area [7]. In the case of male academic allies for female colleagues, this should take into consideration the unique political and societal aspects of faculty at different types of institutions. Potential allies should also engage in self-examination [8]. As mentioned above, a potential ally should examine their motivations for allying with female faculty (our any out-group). Prasad, et al. [9] provide some key pieces of advice for male allies: the importance of education, listening, not self-aggrandizing male efforts, and practicing what you preach. $\mathrm{Ng}$, et al. [2] also provides guidance for allies; they note that allies should show empathy, understand their own identity and privilege, and also highlight listening. It is also important for allies to recognize intersectionality [5]. Anicha, et al. [10] also discuss the importance of acknowledging privilege and power. These acknowledgements are especially important for male faculty allies who are more senior or who have more secure employment positions (e.g., tenured faculty).

Success in the academic environment requires balancing multiple demands (teaching, research, and service) and is dependent on peer review. Allies can help ensure that members of an outgroup are being seen, heard, and receiving credit for different aspects of their scholarship. Allyship can have downsides for members of the in-group given the importance of collegiality in the academy [10]; however, they note that ally programs can improve campus climate for all faculty members. Having allies can enhance feelings of belonging; this was noted for Black women in STEM [11]. Allies can be critical in establishing an identity [8]. This paper and panel examine best practices for male allies of female faculty members.

Advocacy and Allyship for Women 
The reasons for advocating and allying for women in technical fields are typically personal, and may be driven by internal or external forces. The panelists discuss this range of factors in their responses to each of the questions below. Each response has been included in exactly the form that each panelist provided, and then all responses are summarized for each question.

Question \#1 - For what reasons are you an ally or advocate for women in engineering-related fields?

Panelist \#1: For anyone who is underrepresented in their chosen career, it is very hard to overcome imposter syndrome and to advocate for oneself within existing and perceived power and privilege structures. It has been shown that until there is a critical mass of those underrepresented (around 1/3), these issues exist. This means that for women to not only advance in engineering (and ultimately achieve critical mass), they need allies and advocates to help them navigate the unfortunately murky path within these professions. The other reason I am supportive is because I benefitted repeatedly from advocates and allies, both male and female.

Panelist \#2: it is the right thing to do. I consider it a basic rule that I should be an ally and an advocate for others, especially when I have privileges that others don't enjoy. as a white heterosexual cis-gendered male in the US, I have a lot of privilege. anyone who is not white or not heterosexual or not cis-gendered or not male has very likely experienced (and continues to experience) systemic disadvantages that I have not and to which I have been embarrassingly oblivious for most of my life. I feel that, once I know about such systemic disadvantages, I have a moral obligation to act in such a way as to mitigate or eliminate them. to me, there is no middle ground. I am either part of the problem or part of the solution. I can be an opponent of women in engineering or I can be an ally. I choose to try to be an ally. I choose to try, in whatever ways I can, to break down the systems of inequality that prevent all people from attaining the fullness of their possibilities.

Another moral take (it's the right thing to do, part 2): were the tables turned and engineering was dominated by women, I would want women to be allies and advocates for me. there's plenty of moral philosophy that would generally agree that, if I would want women in engineering to be my ally, then I should be an ally to women in engineering. several that come to mind include Kant's categorical imperative (act only according to that maxim whereby you can, at the same time, will that it should become a universal law), the golden rule (do unto others as you would have them do unto you), Gandhi (We but mirror the world. All the tendencies present in the outer world are to be found in the world of our body. If we could change ourselves, the tendencies in the world would also change. As a man changes his own nature, so does the attitude of the world change towards him. This is the divine mystery supreme. A wonderful thing it is and the source of our happiness. We need not wait to see what others do. --> be the change you want to see in the world), Rawls' original position experiment (what kind of society would you want to live in if you do not know which social position you will occupy?), and my personal favorite, the Flying Spaghetti Monster's 3rd I'd really rather you didn't (I'd really rather you didn't judge people for the way they look, or how they dress, or the way they talk, or, well, just play nice, okay? Oh, and get this in your thick heads: Woman = person. Man = person. Samey-samey. One is not better 
than the other, unless we're talking about fashion and I'm sorry, but I gave that to women and some guys who know the difference between teal and fuchsia.).

A third take, this one far less altruistic: more women in engineering is good for me, personally. not in the "the odds are good but the goods are odd" sense, but actually good for my career and my family and the society around me. I have the good fortune to be married to an engineer who is also a woman. I would like to think that I would have ended up an ally of women in engineering (and every other field, too) even if she was not an engineer or we didn't choose each other as life partners, but I'm not so sure. I'd not be here today if not for her and I surely wouldn't have the access and exposure that I have to the experiences of a woman in engineering. so, there's one selfish reason why I advocate for women in engineering: I'm advocating for my partner. her experiences, good and bad, become my experiences. but my selfinterest goes deeper: diversity improves quality. say I want my department to be the best, or at least better than it is now -- by the way, it's pretty great now, but I'm a greedy person so I want more. research shows that diversity within a team improves the quality of that team's work, and this effect appears to hold broadly, in science, medicine, and business. so, my colleagues and I are a team. our perceived "goodness" is a function of the quality (and quantity) of our output: teaching, research, and service. how can we do those things better? one way is to be more diverse. more women in computer science and engineering is only one facet of the diversity that we need, but it's one which we have some control over. as I advocate for women in computer science and engineering, I'm also advocating for more women faculty, for more women in leadership positions, for more diversity so that my department will be better, which, because I am self-interested to the point of narcissism, makes me happy because it makes me look good to be in this high-quality department. and, as a member of society, more women in engineering is good for me because it will lead to better experiences in society. where do you put your purse when you drive? does the seat belt fit you properly? if the airbags deploy, are they aimed at the right place? what temperature is your office? do you get paid parental leave and is it enforced? does your insurance cover infertility treatment? is your doctor familiar with your anatomy and physiology? are your medications safe? whose responsibility is it to prevent unwanted pregnancy? a lot of the world, especially technology, is designed by men for other men. it makes the world not as good for everyone -- for me! -- as it could be.

Panelist \#3: I began working as an advocate for gender equity in 2008 when I was asked to help form an Advocates and Allies group as part of my institution's NSF ADVANCE grant. At that time, my primary motivations were based on personal observations of equity challenges faced by family members, colleagues, and students. It also just seemed to be the right thing to do. Since that time, my reasons for being an advocate have only grown. Having spent considerable time reading the literature and conducting workshops nationwide, I better understand the systemic nature of male-preference gender bias as well as the need to involve majority groups (in this case men) to effect meaningful and lasting organizational change and disrupt and overcome systems of inequity.

Panelist \#4: We know, through research, that historically and currently, women and underrepresented minorities have experienced bias, micro-aggressions, and oppressions in their personal and professional lives. This results in fewer career opportunities, lower pay, and unhealthy work environments. 
There are numerous programs to "help" those who are marginalized - mentorship programs, sponsorships, and employee resource groups for those in industry and mentorship programs, study groups, and gender or based student organizations for those in academia. These programs can certainly benefit the individual but the culture itself is still widely unchanged.

I am an advocate for women and underrepresented minorities because I believe that we all need to be a part of changing the culture so that all feel welcomed, valued, and able to succeed.

Panelist \#5: Women are drastically underrepresented in engineering related fields. This is not for lack of excellence, interest, or ability with girls or women in STEM, but is instead an artifact and result of systemic and institutionalized practices that facilitate the reduction of female interest and participation at all levels of STEM. UC-Berkeley Postdoc Charles Brown says, "The numbers are low, in part, because of forces that tend to drive us from the field. For example, a study [12] has shown that although Black women express more interest in STEM fields when they enter college than do white women, a higher percentage of white women graduate with STEM degrees, which likely indicates the presence of experiences that impede the formation of scientific identity among Black women.” [13] (ref: Physics Today Commentary [14])

I serve to be an ally and advocate for myriad reasons. First, I like to provide support for my female counterparts - I think the genius narrative is perpetuated too much in STEM and can lead individuals to think that if all coursework does not come easy to you then you are not one of the chosen few to excel in this field. I think it's imperative that we illuminate the struggle and share that although multi-variable calculus was indeed a pain, I'm still an excellent scientist and therefore if you're struggling with coursework that doesn't mean you cannot persevere and also be a great engineer. Second, I feel that the entire output of STEM fields are enhanced when we have diverse representation. "an April Proceedings of the National Academy of Sciences study [15] showed that racial minorities produce scientific novelty at higher rates than white men do." (ref: Physics Today Commentary [14]). This flows well into my third reason for serving as an advocate which is to illuminate the complexities of intersectionality as we aim to retain women in STEM. Prof. Kimberle Williams Crenshaw a Prof at UCLA School of Law and Columbia Law School developed the theory of intersectionality in 1989. The main argument in her paper "Demarginalizing the Intersection of Race and Sex: A Black Feminist Critique of Antidiscrimination Doctrine, Feminist Theory and Antiracist Politics" introducing intersectionality was the interconnected nature of an individual's various social identities. This paper focused on black feminism and explains that the experience of being a black woman cannot be understood in terms of being black and of being a woman considered independently but must include the interactions between the two, which frequently reinforce each other leading to unique interdependent systemic oppression and discrimination. Any movement that seeks to advocate for women must have an intersectional approach to support all women inclusive to their gender, racial identity, sexuality, disability and nationality etc. Finally, I love being an engineer, I think it is fun. I've had a few naysayers and hurdles in my way that without proper advocacy and mentorship could have successfully prevented me from achieving my goals and having this fun and interesting job that I have now. I also advocate for women in engineering because I want them to have the opportunity to have fun and learn new things. 
Summary: Advocacy and allyship being "the right thing to do" resonates with all of the panelists. Other points of view point to the data saying that a critical mass of women is needed to overcome power and privilege structures, as well as that the scientific novelty is increased with greater diversity and that intersectionality must be part of the approach.

Question \#2 - What experiences have you had in which you have had to take immediate action as an advocate or ally?

Panelist \#1: In generalities because of confidentiality, there are individual actions and there are systemic actions. As one of the last people in the review process for P\&T, I can sometimes observe where possible bias (or poor structures) have led to unfortunate situations. I have reached out at various levels (above me, below me, to the individual, etc.) to advocate for those faculty and mentor them with the next stages. Another recent example is to advocate for emergency teaching support for caregivers and those affected by the recent racial protests. This led to funding for teaching releases, more graders, etc. to help alleviate the burden. It came late in but I am glad we could do something. Other examples have to do with supporting faculty development towards more inclusive teaching to help female (and other) students in engineering. That said, structural change towards equity is what really needs to happen. This means examining the P\&T process, salaries, other rewards, the curriculum, etc. for existing inequity and then changing the relevant policies and/or providing the necessary faculty/staff development. This is a much longer effort but I suggest it really is the only way to make a sustained difference. Advocating for that level of change is what's needed. As an example, at my previous institution, such advocacy led to a change to scholarship guidelines in engineering to privilege pedagogical scholarship the same as disciplinary scholarship which many of our female faculty had embraced. Currently my institution is engaged in a campus-wide effort to accomplish this level of structural change.

Panelist \#2: thankfully, very few. but, I also worry that I have been oblivious to many. When I taught first-year engineering, the students worked in teams to build a robotic device to carry out some simple task like sorting marbles. sometimes on a team of men and women, I would catch the men engaging in subtle or not-so-subtle exclusion of the women. one of the most common ways this happened was the assumption that the women should be responsible for writing the report while the men built and programmed the device. as this arrangement is suboptimal in just about every way, I would not let it stand whenever I discovered it. usually, simply pointing out what had happened (which was obvious to the women, but not always to the men) was sufficient for the team to self-correct. some teams (particular team members) would require more frequent intervention.

In one of my first-year engineering courses, we had presentation from the women in engineering program and, later, a male student asked "If the wage gap exists, why don't companies hire more women?". I wasn't able to give as full an answer as I wanted to in the moment, so I promised to follow-up with them about it. I went home and talked to my spouse about it and she wrote up her own response - a short essay -- that drew on her own personal experience for me to share with my students, which I did, and it had a very positive effect. I think the man who originally 
asked the question even sent her a thank you note for taking the time to give such a thorough response.

Sometimes, somebody will say to me, or near-enough that I can hear, a comment which implies that women are differently-abled and that this explains some feature of their presence (or lack thereof) in engineering. for example, "women in the software engineering class tend to pick projects that involve helping people because they're more nurturing than the men". "oh, I don't know Guy, don't you think they pick projects the same way most students do: which one will be the easiest or most interesting?" (Guy is a generic pseudonym).

Panelist \#3: When I first began working as a gender-equity advocate, the first action I needed to take was addressing my ignorance of the problem and its related research, so I began reading the literature. As I learned from my reading, I took a hard look at myself to identify areas of deficiency and set goals for improvement. For example, learning Dr. Toni Schmader's research on gender bias in letters of recommendation, I found deficiencies in my own student recommendation letters, and I devised intentional, concrete steps for improvement. As I have become more familiar with the literature, its relevance to myself, and effective steps for improvement, I have also become better at recognizing and effectively addressing issues, both large and small, that occur in a broader institutional context and with my men colleagues.

Panelist \#4: I was hearing from women students at my institution that they were having difficulties working in teams - they were assigned the role of note taker or their technical opinion wasn't being heard in projects. They were also getting told by their peers that their gender was the sole reason they were receiving internships or job offers. I realized that men weren't given the opportunity to hear and digest these stories and then learn why these experiences can be detrimental to their peers and the engineering field overall. I developed and implemented an inclusive leadership course for engineering students, who identify as male, where we talk about identity, bias, power, privilege and microaggressions. The student participants gain an awareness of how these concepts impact themselves as well as those around them. The students define strategies on how to be a more inclusive leader and improve the engineering culture.

Panelist \#5: I have taken actions to change culture of institutions by starting affinity groups and/or events. These groups and events were inspired by my experience of feeling marginalized, by making space for like-minded individuals and allies to gather my experiences at each of these intuitions was enhanced and support for others was formed. While in graduate school, I and classmates founded the Yale League of Black Scientists which gathered black science students at the university to facilitate friendship and mutual support. We hosted outreach events for underrepresented students in the New Haven area and "in-reach" events to facilitate our academic success, too. Similarly, I founded the Minority Carriers panel luncheon at the IEEE Photovoltaics' Specialist Conference. One of the primary goals of the Minority Carriers program is to provide a platform for marginalized individuals to find community within PVSC. Another goal is to offer a keynote address that will provide attendees with professional development and career guidance that acknowledges intersectionality and the nuances of diversity today. 
To date I have only had to immediately take action to serve as an advocate for myself. While in graduate school I was the recipient of many attacks rooted at the intersection of my identity as a black woman. I have had to defend myself at times against tenured professors and illuminate maltreatment and disrespect. The most frequent abuses I have experienced were at the hands Staff Researchers that direct and maintain campus user facilities (like a cleanroom, or an optical analysis laboratory). A Staff Researcher or technician (white males in my instances) either threw away equipment while I was using it (disposing of my gloves while I was using the scanning electron microscope) or antagonizing and questioning my "right" to be in the space, in an instance where I was using an $\mathrm{x}$-ray diffraction tool in a characterization laboratory.

Summary: Panelists describe both internal reflection and external corrective action that has needed to be taken, often related to stereotyped roles in teams. The existence of structural barriers was cited as a root of the issues experienced. Once again, the intersectional challenges faced by women of color highlights the importance that it is not as simple as addressing only one aspect of diversity, equity, and inclusion.

Question \#3 - What do you recommend for easy-to-implement actions to advocate?

Panelist \#1: There is no such thing as easy-implement actions if you want to have real impact when it comes to existing inequity in higher ed and in particular within engineering.

\section{Panelist \#2:}

- Listen and believe. if someone tells you about an experience they had as a woman in engineering, listen and believe. don't judge. it may sound outrageous or it may not seem like a big deal to you. either way, resist the urge to downplay it or attempt to solve it. just listen and believe.

- Speak up to promote and recognize women in engineering. pay attention to the accomplishments of women in engineering and use your voice (your seat at the table, your privilege) to share those accomplishments with others.

- Check yourself. spend some time (a day or a week) using only gender-neutral pronouns (they, them, theirs). consider how this affects the way you speak about others and whether there are other ways in which you speak or write that are gendered. for example, when I write a letter of recommendation, I use the same set of words to describe the student's qualities regardless of gender: leadership, intelligence, perseverance. consider other ways in which your own personal biases affect your treatment of women in engineering. being aware of your biases helps you to counter them and will improve your advocacy.

- Become aware of mansplaining, manterrupting, and bropriation. use amplification (repeat the ideas of women and give credit to the women who came up with them) to counteract them.

- Join SWE. the society of women engineers is the world's largest advocate for women in engineering and technology. get involved. if your school doesn't have a student chapter of SWE, offer to help start one and be an advisor

- Join WIED, the women in engineering division of ASEE.

- Join WEPAN, women in engineering proactive network. 
- Invite engineers who are women to speak to your classes. SWE, WIED, and WEPAN can help you do this.

Panelist \#3: There are so many things that we, as men, can do to support gender equity. My first recommendation is to make gender equity a personal priority and read the relevant literature. I recommend that we as men first look inward, to our own attitudes, behaviors, and actions, and that we each set regular concrete goals for self-improvement. Identify a goal, write it down, and put it somewhere that you will see it every day; I try to set at least one new goal every year or semester. These goals and actions are often simple to state but sometimes are difficult to achieve, so intentionality is key. Some example goals include: reading a relevant gender-equity article or attending a gender-equity event every month, practicing better listening during meetings, volunteering to take minutes during meetings, taking responsibility for genderequitable practices while serving on hiring or review committees, practicing inclusivity by personally inviting new colleagues into your professional activities, nominating overlooked colleagues for awards and honors, volunteering to reduce the service loads of overworked colleagues, and holding ourselves and our men colleagues accountable.

Panelist \#4: One of the easiest actions that an advocate and ally can do is listen (really listen) and validate. If you see or hear something that could be offensive to someone else, reach out to that person. Take cues from that person about how you can support. This doesn't automatically mean that they want you to step in to help or intervene. Let them tell you what they need - if anything. If you find yourself engaging in a negatively biased behavior (and we all do have bias so this is expected!), stop the behavior and apologize. Don't defend or make excuses, just apologize and try to do better. Be the person in the meeting who makes sure that every voice is heard. A small but important action.

\section{Panelist \#5:}

- Admit and hire more women, and women of color. Women should not be viewed as risks, but instead as great thinkers with immense potential. Support the women that you have in your program or on your faculty. Different people need different support but different does not make something less. Plants have different needs as far as water and sunlight but they all provide food, beauty, and oxygen.

- Educate yourself. Read feminist literature, read literature about the history of racism in the united states. Listen to women who are willing to share their stories and voice their concerns, then believe those women. Don't let confirmation bias fool you. Remember that one woman's opinion is one woman's opinion, we are individuals with different experiences, expectations etc. - if one woman says the department is "fine" your work is not done - go talk to more women, better yet - find the woman that left the department and figure out why.

- Use power, influence, and privilege to change culture and climate for the better. Abolish patriarchal framework. Become anti-sexist, anti-mysogynoirist, anti-misogynist.

- Put your money where your mouth is. If you "value diversity and inclusion" PAY FOR IT. We are moving away from the model that lip serves that D\&I is important but it's treated like an add on when overburdened Jr faculty (usually women and underrepresented minorities) are saddled with the tasks of serving on committees and task forces or with educating entire departments. Bring in specialists and experts and 
academics for talks and consultations and pay them honoraria or rates commensurate with their expertise.

- A challenge is that sexism and racism are viewed as a character flaw, but that has muddled the waters. People become defensive when they're called out for saying something racist or sexist because no one considers themselves a bad person. We need to normalize that someone can be called for a micro/macro- aggression and still not have an indelible mark against their entire character. Those criticisms may be received with much less hostility.

- An ally and advocate are different. An ally reacts and responds to attacks, an advocate is proactive. An advocate nominates you for awards, positions, extends collaborative work to you. An advocate helps position people for future success.

- Personal transformations can start late in life, first by learning about privilege particularly white male privilege. Learn how privilege impacts your interactions with others. Educate yourself, learn what microaggressions are. Ask yourself "is this something I could change?". A great deal of scholarship is widely available for free on these topics, there is not a shortage of information. Start with direct actions, be a good listener, and have empathy.

- Understand that this movement is not about you. Your discomfort does not take precedent over doing the right thing and having difficult discussions and taking the necessary actions. It can't be about you. Use your voice to amplify the voices that are drowned out. Assist and amplify.

Summary: The panelists believe that nothing is "easy" about addressing these inequities. That being said, the panelists stress looking inward and amplifying outward. Listening, being proactive, and understanding cost and ownership of DEI efforts are critical to moving these efforts forward.

Question \#4 - How can advocates and allies help implement change at their own institutions?

Panelist \#1: Reach out to those who are experts on diversity equity and inclusion. These folks exist at your institution and are often not in STEM. You need expert advice and leadership to change systemic inequity or it's just media highlights. Listen to them and help them advocate for the structural change that is needed. This is my biggest lesson over the last 18 months (in my new position).

\section{Panelist \#2:}

- nominate women for leadership positions.

- include women on committees that make policy or provide advice to policy-makers. if you serve on such a committee and there are no women, ask that women be appointed. when you are soliciting feedback in preparation for a decision in the committee, go the extra mile to get feedback from women. when feedback is solicited from you, take a moment to consider how you can use this as an opportunity to advocate for women in engineering (e.g. talk to women in engineering so your responses can echo theirs).

- model good behavior and be accountable to your students and colleagues. hold your students, colleagues, and administration accountable. 
- report systemic bias whenever you see it or hear about it.

- question the claim that change takes time. it might, but under certain conditions, typically-slow-moving institutions have been observed to change rapidly.

Panelist \#3: Change does not happen by wishful thinking or accident. It requires intentional commitment and effort. Advocacy is more something that we do than something we are. We each need to choose a set of purposeful priorities and actions that are sustainable for our own situation. It is difficult to change behaviors, so adopting modest initial goals will be more effective than having overly ambitious goals that you will never achieve. As your knowledge and comfort grow, so too will your capacity and scope for action. Let colleagues know of your commitment to and value of gender equity and encourage them to join you in working toward a gender-equitable institution. As the people within an institution change, so too will the institution change.

Panelist \#4: Start conversations around allyship or advocacy. Use formal mechanisms from outside the institution such as training through the North Dakota State University Advocates and Allies program or the White Men as Full Diversity Partners. If your institution has a multicultural center, a diversity office, a human resources office, ask for resources for bias training for your employees. Create an inclusive excellence program with a rewards structure. Start a book discussion over lunch - the topic could be around inclusive teaching, inclusive leadership, women in leadership etc. There is not one right solution. These are all strategies that our university is currently participating in. Remember Ruth Bader Ginsburg: "Real change, enduring change, happens one step at a time."

\section{Panelist \#5:}

- Diversify your own team or laboratory. Lead by example.

- Use power, influence, and privilege to change culture and climate for the better by implementing policies that create inclusive environments that allow women to thrive. Abolish patriarchal framework. Become anti-sexist, anti-mysogynoirist, antimisogynist.

- Be an active bystander. Openly and frequently challenge colleagues who antagonize women in STEM.

- Actively champion women for positions, awards, etc. - say their names behind closed doors. Nominate women for awards that aren't just awards for women. Reach out to women with opportunities for their professional advancement.

Summary: To implement change at an institution, actively leading by example is crucial. Continuing to educate oneself and engaging with experts will help guide those actions. The efforts must be in the open and conversational.

\section{Conclusions}

Advocacy and allyship for women in engineering is explored through questions to five panelists with expertise in this area. Their responses show that advocacy and allyship is not an easy path at this point in time, and has many facets to consider. It is an intentional choice that is 
considered both the right thing to do as an empathetic person and the better path forward with respect to product and process design.

While any action takes commitment to the reasons for that action, being strong for oneself and amplifying the actions of minimized others was noted by multiple panelists. Educating oneself and facing one's own inadequacies will facilitate self-improvement. Listening and creating ways for others to learn about their own biases and privilege is required to move the needle on improving the conditions for women in engineering.

Panelists also stressed that advocacy and allyship must be intersectional and multi-faceted. A solution is not "one size fits all" if it addresses only certain biases and social dynamics, nor if it only happens when it is publicized. Engage experts to become equipped for implementing change, and then make it the culture through constant vigilance. Panelists agree that actions speak louder than words.

This paper described steps to take and actions to implement so that more people, and men especially, can advocate and ally for women in engineering and related disciplines, as well as understanding that diversity, equity, and inclusion does not stop with just this one demographic factor.

\section{References}

[1] W. R. Louis et al., "Emerging research on intergroup prosociality: Group members' charitable giving, positive contact, allyship, and solidarity with others," Social and Personality Psychology Compass, vol. 13, no. 3, Mar 2019, Art no. e12436, doi: 10.1111/spc3.12436.

[2] W. Ng, S. M. Ware, and A. Greenberg, "Activating Diversity and Inclusion: A Blueprint for Museum Educators as Allies and Change Makers," Journal of Museum Education, vol. 42, no. 2, pp. 142-154, 2017, doi: 10.1080/10598650.2017.1306664.

[3] M. A. Craig, V. Badaan, and R. M. Brown, "Acting for whom, against what? Group membership and multiple paths to engagement in social change," Current Opinion in Psychology, vol. 35, pp. 41-48, Oct 2020, doi: 10.1016/j.copsyc.2020.03.002.

[4] H. R. M. Radke, M. Kutlaca, B. Siem, S. C. Wright, and J. C. Becker, "Beyond Allyship: Motivations for Advantaged Group Members to Engage in Action for Disadvantaged Groups," Personality and Social Psychology Review, vol. 24, no. 4, pp. 291-315, Nov 2020, Art no. 1088868320918698, doi: 10.1177/1088868320918698.

[5] J. Carlson, C. Leek, E. Casey, R. Tolman, and C. Allen, "What's in a Name? A Synthesis of "Allyship" Elements from Academic and Activist Literature," Journal of Family Violence, vol. 35, no. 8, pp. 889-898, Nov 2020, doi: 10.1007/s10896-019-00073-z.

[6] A. D. Berkowitz, "Fostering men's responsibility for preventing sexual assault," in Preventing violence in relationships: Interventions across the life span., P. A. Schewe Ed. Washington, DC: American Psychological Association, 2002, pp. 163-196.

[7] M. Kutlaca, H. R. M. Radke, A. Iyer, and J. C. Becker, "Understanding allies' participation in social change: A multiple perspectives approach," European Journal of Social Psychology, vol. 50, no. 6, pp. 1248-1258, Oct 2020, doi: 10.1002/ejsp.2720. 
[8] A. J. Forber-Pratt, C. O. Mueller, and E. E. Andrews, "Disability Identity and Allyship in Rehabilitation Psychology: Sit, Stand, Sign, and Show Up," Rehabilitation Psychology, vol. 64, no. 2, pp. 119-129, May 2019, doi: 10.1037/rep0000256.

[9] A. Prasad et al., "What are men's roles and responsibilities in the feminist project for gender egalitarianism?," Gender Work and Organization, p. In Press, 2021, doi: 10.1111/gwao.12573.

[10] C. L. Anicha, A. Burnett, and C. Bilen-Green, "Men Faculty Gender-Equity Advocates:A Qualitative Analysis of Theory and Praxis," The Journal of Men's Studies, vol. 23, no. 1, pp. 21-43, 2015, doi: 10.1177/1060826514561974.

[11] I. R. Johnson, E. S. Pietri, F. Fullilove, and S. Mowrer, "Exploring Identity-Safety Cues and Allyship Among Black Women Students in STEM Environments," Psychology of Women Quarterly, vol. 43, no. 2, pp. 131-150, Jun 2019, doi:

$10.1177 / 0361684319830926$.

[12] L. T. O'Brien, A. Blodorn, G. Adams, D. M. Garcia, and E. Hammer, "Ethnic Variation in Gender-STEM Stereotypes and STEM Participation: An Intersectional Approach," Cultural Diversity and Ethnic Minority Psychology, vol. 21, no. 2, pp. 169-180, 2015, doi: 10.1037/a0037944.

[13] K. D. da Rosa, "Gender, Ethnicity, and Physics Education: Understanding How Black Women Build Their Identities as Scientists," Ph.D. Dissertation, Dept. Education, Columbia University, New York, NY, 2013.

[14] C. D. Brown II, "Commentary: Disentangling anti-Blackness from physics," Physics Today, 20 July 2020, doi: 10.1063/PT.6.3.20200720a.

[15] B. Hofstra, V. V. Kulkarni, S. Munoz-Najar Galvez, B. He, D. Jurafsky, and D. A. McFarland, "The Diversity-Innovation Paradox in Science," Proceedings of the National Academic of Sciences, vol. 117, no. 17, pp. 9284-9291, April 2020, doi: 10.1073/pnas.1915378117. 